\title{
Myopia of prematurity: nature, nurture, or disease?
}

Recent clinical research has shown that the degree of myopia is significantly less following laser therapy when compared with cryotherapy for severe retinopathy of prematurity (ROP). ${ }^{12}$ This important finding is confirmed by Laws et al in this issue of the BfO (p 12). While the associations of prematurity, ROP, and myopia are well known, they are not precisely defined and mechanisms are even less well understood - an ideal opportunity for us to delve briefly into the evidence.

Myopia is probably the normal refractive state in infants before full term $^{34}$ with the eye becoming more hypermetropic in early infancy. Compared with the eye of the full term baby the features of this myopia are shorter axial length, flatter anterior chamber, and more spherical lens. ${ }^{4}$ The term myopia of prematurity is not applied to this physiological and temporary type of myopia.

Over three decades ago Fledelius studied a cohort of preterm babies and observed a disproportionate number of myopes; he found that this refractive state persisted even to 18 years of age. ${ }^{5}$ This type of myopia, myopia of prematurity (MOP), has an early onset and compared with full term and juvenile onset myopes the MOP eye exhibits a relatively highly curved cornea, shallow anterior chamber, and thick lens. Axial lengths are shorter than expected for the dioptric value. ${ }^{6}$ The hallmark of MOP is arrested development of ocular anterior segment. With refreshing honesty Fledelius, in $1996,{ }^{7}$ stated that owing to a paucity of neonatal data in his early study it was not categorically known whether the MOP in this cohort was, or was not, associated with previous ROP. It is now confirmed that MOP without previous ROP does occur, ${ }^{7-11}$ and at higher frequencies than in the full term population, and with the characteristics described above. ${ }^{12}$

Few reports on the refractive outcome contain detailed information of the neonatal period. Laws et $a l^{13}$ studied ROP stage and refractive outcome at 6 months' corrected age and found that while there was a trend for increasing myopia with ROP presence and severity, this only reached significance with stage 3 . Several authors have reported that there is a dramatic jump in the prevalence of myopia when stage 3 ROP is reached. ${ }^{79^{111}}$ To cite one study ${ }^{9}$ the incidence of myopia by ROP stage was as follows: none $13 \%$; mild ROP $<20 \%$, stage 3 ROP $>44 \%$. Of particular interest is the high incidence of myopia in both cryotherapy treated and non-treated eyes with severe ROP. ${ }^{81516}$ This is quite distinct from the outcome after laser therapy as shown by Laws et al and others. ${ }^{12}$ Acknowledging the large data spread, these differences are not trivial, with refractions at 1 year after laser of -0.50 and -0.37 dioptres (right and left eyes), compared with -5.25 and -6.00 (right and left eyes) following cryotherapy (Laws et al, this issue).

Many theories have been put forward to explain how myopia develops in premature babies. These include bone deficiency, temperature, light, visual deprivation, and retinal dysfunction. Pohland $\mathrm{t}^{17}$ speculated that MOP could be attributed to postnatal bone mineral deficiency, an idea which unsurprisingly generated a sharp critique. ${ }^{18}$ Secondly, preterm neonates experience a temperature deficit ${ }^{19}$ at a time when corneal growth is especially active. While we can speculate that this deficit might impede corneal growth, it is most unlikely that it fully explains MOP. Furthermore, while this temperature deficit affects all such babies myopia is not an invariable sequela of preterm birth. This last point also mitigates against light exposure as a myopiagenic factor. While light is known to influence eye growth in chickens, ${ }^{20}$ and preterm neonates are generally exposed to high levels of non-cycled lighting, ${ }^{21}$ its role for human eye growth is unknown. Visual deprivation is, in our opinion, an unlikely candidate as a cause of either MOP or ROP induced myopia, not least because normal vision in preterm neonates is so low that it is relatively insensitive to blur and deprivation. Thus, macular haemorrhage (even unilateral) in full term neonates does not adversely influence visual ${ }^{22}$ or refractive development. ${ }^{23}$ Macular haemorrhage permits peripheral retinal function, but it is interesting to note that more generalised deprivation such as a dense vitreous haemorrhage does cause myopia, but this has been reported only in older babies and children, and only if it persists for months. ${ }^{24}$ It has been postulated that even mild acute ROP renders the posterior retina dysfunctional possibly by retarding photoreceptor maturation and migration ${ }^{25}$ and 'so alters eye growth signals'. While we cannot agree with or refute this general statement, it does not marry with the data on ROP stage and refractive development.

ROP induced myopia cannot be fully explained by increased axial length as it is also associated with evidence of arrested development of the anterior segment: microcornea, steep corneal curvature, thickened lens. ${ }^{26-29}$ This points to a mechanical restriction of ocular growth. Supportive evidence comes from the non-linear refractive development associated with ROP. As the prevalence of myopia rises sharply as stage 3 is achieved, so does the prevalence of anisometropia, and astigmatism. ${ }^{13}$ The last exhibits a greater than normal spread of axis-with a tendency for the axis to rotate according to the location of ROP residua. ${ }^{13}$ It could be argued that the mechanical effect is exerted by the ROP lesion which is located in that portion of the globe where maximum growth occurs in late fetal and early postnatal life. Restricted growth in this region would be expected to inhibit growth of both the anterior sclera and the anterior segment.

What can account for the differential refractive outcome of cryotherapy and laser? Trans-scleral cryotherapy is more tissue destructive ${ }^{30}$ compared with laser. ${ }^{31}$ Cryo applications are large and confluent. Laser lesions are smaller, discrete, and, as they are spaced by lesion-sized gaps, ${ }^{32}$ it could be argued that this is less likely to impede ocular growth.

To summarise, three types of myopia are associated with premature birth: (1) physiological and temporary myopia (nature); (2) myopia without ROP (MOP; nurture); and (3) myopia induced by severe ROP (disease). That laser results in less myopia than cryotherapy is clinically important. However, it is also important to appreciate that both cryotherapy and laser offer significant benefit to the eye at risk of blindness due to severe ROP. Clearly, there is vital work to do not only with regard to refractive development, but also to determine the visual outcome of these babies who are nurtured in an abnormal environment and may suffer a range of severe visual pathway complications. So, returning to the title of this editorial, it is hopefully now apparent that nature, nurture, and disease all contribute to myopia associated with prematurity - we need to know more.

ALISTAIR R FIELDER

Imperial College School of Medicine at St Mary's, Academic Unit of Ophthalmology, Western Eye Hospital, London NW1 5YE

GRAHAM E QUINN

Division of Pediatric Ophthalmology,

Children's Hospital of Philadelphia,

University of Pennsylvania, Philadelphia, USA 
1 Algawi K, Goggin M, O'Keefe M. Refractive outcome following diode laser versus cryotherapy for eyes with retinopathy of prematurity. Br f Ophthalversus cryotherapy for
mol 1994;78:612-4.

2 Ling CS, Fleck BW, Wright E, Anderson C, Laing I. Diode laser treatment for retinopathy of prematurity: structural and functional outcome. $B r \mathcal{F}$ Ophthalmol 1995;79:637-41.

3 Scharf I, Zonis S, Zeltzer M. Refraction in premature babies. Metab Ophthalmol 1978;2:395-6.

4 Fledelius HC. Pre-term delivery and the growth of the eye. An oculometric study of eye size around term-time. Acta Ophthalmol 1992;204(Suppl):10-5.

5 Fledelius HC. Myopia of prematurity - changes during adolescence. A longitudinal study including ultrasound. Doc Ophthalmol Proc Series 1981;29:217-23.

6 Fledelius HC. Changes in refraction and eve size during adolescence. With special reference to the influence of low birth weight. Doc Ophthalmol Proc Series 1981;28:63-9.

7 Fledelius HC. Pre-term delivery and subsequent ocular development. A 7-10 year follow-up of children screened 1982-84 for ROP. 3) Refraction. 7-10 year follow-up of children screened 1982-84 for ROP. 3) Re

8 Nissenkorn I, Yassur Y, Mashkowski D, Sherf I, Ben Sira I. Myopia in premature babies with and without retinopathy of prematurity. Br f Ophthalmol 1983;67:170-3.

9 Quinn GE, Dobson V, Repka MX, Reynolds J, Kivlin J, Davis B, et al. Development of myopia in infants with birth weights less than 1251 grams. Ophthalmology 1992;99:329-40.

10 Gallo JE, Fagerholm P. Low-grade myopia in children with regressed retinopathy of prematurity. Acta Ophthalmol 1993;71:519-23.

11 Robinson R, O'Keefe M. Follow up study on premature infants with and without retinopathy of prematurity. Br f Ophthalmol 1993;77:91-4.

12 Fledelius HC. Pre-term delivery and subsequent ocular development. A 7-10 year follow-up of children screened 1982-84 for ROP. 4) Oculometric - and other metric considerations. Acta Ophthalmol Scand 1996;74:301-5.

13 Laws D, Shaw DE, Robinson J, Jones HS, Ng YK, Fielder AR. Retinopathy of prematurity: a prospective study. Review at six months. Eye 1992;6:47783 .

14 Cryotherapy for Retinopathy of Prematurity Cooperative Group. The natural outcome of premature birth and retinopathy. Status at one year. Arch Ophthalmol 1994;112:903-12.

15 Seiberth V, Knorz MC, Trinkmann R. Refractive errors after cryotherapy in retinopathy of prematurity. Ophthalmologica 1990;201:5-8.
16 Cryotherapy for Retinopathy of Prematurity Cooperative Group. Multicenter trial of cryotherapy for retinopathy of prematurity. $3 \frac{1 / 2}{2}$ year outcome-structure and function. Arch Ophthalmol 1993;111:339-44.

17 Pohlandt F. Hypothesis: myopia of prematurity is caused by postnatal bone mineral deficiency. Eur F Pediatr 1994;153:234-6.

18 Gerding $\mathrm{H}$, Busse $\mathrm{H}$. Myopia of prematurity (MOP) is definitely not a consequence of skull deformation. Eur F Pediatr 1995;154:245-6.

19 Fielder AR, Levene MI, Russell-Eggitt IM, Weale RA. Temperature-a factor in ocular development? Dev Med Child Neurol 1986;28:279-84.

20 Stone RA, Lin T, Desai D, Capehart C. Photoperiod, early post-natal eye growth, and visual deprivation. Vis Res 1995;35:1195-202.

21 Fielder AR, Foreman N, Moseley MJ, Robinson J. Prematurity and visual development In: Simons K, ed. Early visual development, normal and abnormal. New York: Oxford University Press, 1993:485-504.

22 Billson FA, Fitzgerald BA, Provis JM. Visual deprivation in infancy and childhood: clinical aspects. Aust NZ F Ophthalmol 1985;13:279-86.

23 Von Noorden GK, Khodadoust A. Retinal hemorrhage in newborns and organic amblyopia. Arch Ophthalmol 1973;89:91-3.

24 Miller-Meeks MJ, Bennett SR, Keech RV, Blodi CF. Myopia induced by vitreous hemorrhage. Am f Ophthalmol 1990;109:199-203.

25 Lue C-L, Hansen RM, Reisner DS, Findl O, Petersen RA, Fulton AB. The course of myopia in children with mild retinopathy of prematurity. Vis Res 1995;35:1329-35.

26 Hittner HM, Rhodes LM, McPherson AR. Anterior segment abnormalities in cicatricial retinopathy of prematurity. Ophthalmology 1979;86:803-16.

27 Gordon RA, Donzis PB. Myopia associated with retinopathy of prematurity. Ophthalmology 1986;93:1593-8.

28 Kelly SP, Fielder AR. Microcornea associated with retinopathy of prematurity. Br $\mathcal{F}$ Ophthalmol 1987;71:201-3.

29 Laws DE, Haslett R, Ashby D, O'Brien C, Clark D. Axial length biometry in infants with retinopathy of prematurity. Eye 1994;8:427-30.

30 Nissenkorn I, Kremer I, Ben Sira I, Cohen S, Garner A. A clinicopathological case of retinopathy of prematurity (ROP) treated by peripheral cryopexy. Br f Ophthalmol 1984;68:36-41.

31 Benner JD, Huang M, Morse LS, Hjelmeland LM, Landers MB. Comparison of photocoagulation with the argon, krypton, and diode laser indirect oph thalmoscopes in rabbit eyes. Ophthalmology 1992;99:1554-63.

32 McNamara JA. Laser treatment for retinopathy of prematurity. Curr Opin Ophthalmol 1993;4:76-80.

\section{Cataract and driving}

Onset of cataract and its surgery have both practical and legal consequence for driving. In the UK the need to satisfy the number plate test is absolute in law (a standard number plate of $79.4 \mathrm{~mm}$ in height at 20.5 metres in good daylight). Empirically found to be equivalent to 6/10 Snellen, ${ }^{1}$ the test is consistent with the European Union (EU) Directive (now law), ${ }^{2}$ which requires a minimum acuity of 0.6 metric $(=6 / 10$ Snellen), as well as a minimum field of vision of $120^{\circ}$.

The paper in this issue of the $B \mathcal{F O}$ by Mönestam and Wachtmeister ( $p 16$ ), states a legal requirement for Sweden as $0.5(6 / 12$ Snellen) at the time of the study, though Sweden is now subject to the EU directive (and 0.6 acuity). This variation does not detract from the value of their paper which investigates driver patients' largely subjective estimation of their visual function while driving, as well as their actual visual acuities both before and after modern cataract surgery. It is to some extent a measure of their driver patients' needs from cataract surgery as well as their expectations. The latter are sometimes unrealistically high in UK experience. Their results show a commendably high standard of visual improvement for driving. In the light of driving safety the authors show the real value of pseudophakic cataract surgery, as well as the value of surgery for the second eye. They look specifically at the problems of estimating distance, which is of some importance in driving and is relevant to other research-for example, into 'estimated time to collision', and other psychophysical factors. ${ }^{3}$

Interestingly, their paper records $23 \%$ of patients before surgery who continued driving while below the national standard, a not unknown clinical finding in the UK. They find little correlation between visual acuity and difficulty in driving before surgery; perhaps a reflection of the weak statistical correlation of the multifactorial visual factors to driving accidents. ${ }^{45}$

The authors reasonably rely on much very subjective data, bearing in mind the subjective nature of visual perception itself. Perception is at least as important as vision in driving. New studies and methods to test drivers' visual perception are beginning to emerge-for instance, 'usable field of view' and driving simulation. ${ }^{67}$

There are, of course, other factors to be addressed in the context of cataract surgery and driving - that is, the role of contrast, and also discomfort and disability glare in both bright daylight and from oncoming headlights. ${ }^{89}$ Glare in some of these circumstances can produce both optical flare (and disability glare) as well as diffraction effects from headlamps and street lamps, both before and after surgery. Brightness acuity and glare tests have been used to assess both discomfort and visual function for driving in glare conditions. ${ }^{1011}$

Personal investigation has shown glare and diffraction effects can be quite serious in early cortical and, especially, cuneiform cataracts. These indicate the value of the number plate test as a practical visual acuity and square wave contrast sensitivity test in the real highway environment. ${ }^{8}$ The same investigations have shown that diffraction lines occur with bright sources such as headlamps, street lighting, and surface water reflections. These are also significant after extracapsular surgery where there are capsule traction lines present. The angle of the diffracted flare line can be directly related to the traction line axis. Capsule pearls can produce a more diffuse flare and disability 